\title{
EDITORIAL
}

\section{On some risks in risk research ${ }^{1}$}

Schizophrenia is essentially a disorder of development - one in which genes and environment in interaction are the prime determiners of its developmental course. Although this framework for theory has had a lengthy history, the empirical, efforts to trace such development have been heavily biased by an overemphasis on retrospections provided by patients, parents and family members. This method has origins that are rooted in the history of psychiatry (Garmezy \& Streitman, 1974), and, although widely used, its biasing properties have been long known to psychiatric researchers. It required, however, the systematic accounts of normal mothers reflecting on the early years of their normal children to render unequivocal the dangers inherent in leaning on parental memory for a reconstruction either of significant life events or of personality attributes characteristic of the growing offspring (Yarrow et al. 1970).

These studies have revealed the distortions in recall produced by the passage of time, the biasing influence of contemporary adaptation of an offspring on a parent's recital of earlier adjustment, and the effect of contemporary child-care values on the remembrance of things past. The likelihood that such distortions would be heightened in parents recalling the early life patterns of an offspring who had subsequently developed a psychosis simply accentuated the need for systematic ongoing evaluations of children who were presumed to have a heightened predisposition for subsequent psychopathology. Hence the growth of risk research in the study of schizophrenia, an area that follows in a tradition set by investigators of predisposition to other forms of disorder such as delinquency or cognitive and adaptational deficits induced by pregnancy and birth complications (Birch \& Gussow, 1970; Pasamanick \& Knobloch, 1961). The rapid growth of studies of risk for schizophrenia has been chronicled elsewhere (Garmezy \& Streitman, 1974; Garmezy, 1974), but it would be inappropriate to suggest that this specific research focus lacks historical precedent.

\section{THE HISTORICAL SETTING}

In his scholarly treatise on Dementia Praecox and Paraphrenia, Kraepelin (1919) provided a masterly description, requiring some 250 pages, of the symptomatology of dementia praecox. Then in a concluding chapter, only $4 \frac{1}{2}$ pages in length, provocatively titled 'How to combat it', Kraepelin assigned a paragraph headed 'Prophylaxis' to a 199-word commentary on children at risk for the disorder:

In children of such characteristics as we so very frequently find in the previous history of dementia praecox, one might think of an attempt at prophylaxis especially if the malady had been already observed in the parents or brothers and sisters. Whether it is possible in such circumstances to ward off the outbreak of the threatening disease, we do not know. But in any case it will be advisable to promote to the utmost of one's power general bodily development and to avoid one-sided training in brain work, as it may well be assumed that a vigorous body grown up under natural conditions will be in a better position to overcome the danger than a child exposed to the influences of effeminacy, of poverty, and of exact routine, and especially of city education. Childhood spent in the country with plenty of open air, bodily exercise, escalation beginning late without ambitious aims, simple food, would be the principal points to keep in view. Meyer, who regards dementia praecox essentially as the effect of unfavourable influences of life and education on personalities with abnormal dispositions, hopes by all these measures to be able to prevent the development of the malady (p. 253).

1 Address for correspondence: Dr Norman Garmezy, Department of Psychology, N419 Elliott Hall, University of Minnesota, Minneapolis, Minnesota 55436, USA. 
Contained within this single paragraph are a number of conjectures which, in part, are the forerunners of aspects of contemporary research on children at risk for schizophrenia. Three stand out. First, the passage defines the criterion for the current dominant mode of identifying risk, namely the presence of the 'malady' in parents. Secondly, there is the acceptance of a diathesis-stress formulation for the disorder; abnormal genetic dispositions linked to unfavourable environments predispose the child to dementia praecox in later life. Thirdly, there is a mild acceptance of the concept of primary prevention via attempts to undo those stressors which define the unfavourable environments: inappropriate gender identity, social isolation, an over-ideational world marked by compulsive routine, too high a level of aspiration (presumably with its attendant frustrations), a failure to participate in play, and the confining effects of city life with its debilitating patterns of poverty, deprivation and disadvantage.

Kraepelin's portrait etched in the first decades of the twentieth century only partially fits the frame of the mid-70s, for what is missing are two components very evident in current risk studies. The first relates both to selection for risk and to the content of studies and can be expressed by two questions: (1) What methods, other than manifest schizophrenia in parents, can be used to select children with a heightened risk for schizophrenia in adulthood? (2) Which variables can best be used in ongoing studies to differentiate subsets of children at risk from their less vulnerable contemporaries? The second component is represented by a striking shift in the method of investigation, namely the emphasis on longitudinal studies to evaluate the ongoing processes of growth and adaptation in these children.

Kraepelin provides only a portion of the historical picture. The second and third decades of the century witnessed the efforts of other investigators who were bent on studying the effects of parental pathology on children. The classical studies of Bender (1937) were preceded by the work of Canavan \& Clark (1923), Ramage (1925), Preston \& Antin (1932) and Lampron (1933). Shakow (1972) has also provided a brief account of the early efforts of a core group of investigators associated with the famed Worcester State Hospital research programme on schizophrenia to study 95 infants who had been born to mothers hospitalized for schizophrenia in the mental institutions of Massachusetts from 1927 to 1936. During this same era, but under very different circumstances, Aubrey Lewis (1957) began a programme of research on the offspring of parents both of whom were mentally ill.

Clearly the study of risk for schizophrenia has its forebears and is part of more recent research traditions in the study of the disorder. Today numerous programmes emphasizing the developmental study of children are underway in various nations, including Canada, Denmark, Israel, Mauritius, Sweden and the United States (Garmezy, 1974, 1975).

As these programmes have matured, researchers have become increasingly aware of specific problems of concept, method and content associated with the evaluation of risk potential in children. These pose some of the risks in risk research, several of which led Lewis (1957) to begin his paper 'diffidently' in recognition of the research realities he had encountered. These risky features form the basis of this editorial commentary.

\section{THE PROBLEM OF THE SELECTION OF INDEX CHILDREN}

How best to define risk potential has been a continually vexing problem for investigators. The criterion overwhelmingly used by all but one or two investigative teams is that of a determinate history of manifest schizophrenia in a parent, typically the mother. The use of this criterion is essentially a pragmatic one. It follows no specific genetic model but is based upon multiple empirical studies that have been conducted within a genetic framework. These reveal that by using the parental criterion one can raise the anticipated incidence rate to some $10 \%$ for schizophrenia as opposed to a figure slightly below $1 \%$ when randomly selected individuals are used. Actually, the $10 \%$ figure will vary depending, among other things, on the adaptational status of the non-schizophrenic spouse 
(Kallman, 1938; Lewis, 1957; Mednick, 1973), but the value constitutes an average of several genetically oriented studies.

There are several observations worth making about this almost exclusive reliance on the parentaldisorder criterion. (1) Knowledge of the non-psychotic parent's diagnostic status often cannot be determined so that additional stressful or ameliorating factors for the offspring may not be known to the investigator. Not that risk investigators don't try, but factors of non-cooperation, absence from the home, and the unavailability of psychiatric registries often block the acquisition of much needed information. (2) The use of dual-mated pairs which would appreciably raise the projected incidence figure in offspring to approximately $40 \%$ poses inordinately difficult logistical problems, including those related to paternal identification, limited numbers of available offspring, geographical dispersion of families, wide sampling variations in age and ethnicity etc. As a result, only one hardy investigator has attempted to secure such a critical sample of truly high-risk children (Erlenmeyer-Kimling, 1975). (3) As Shields (1977) points out in his accompanying editorial, only a minority of adult schizophrenics have had a schizophrenic parent. Although selection for risk based on alternative models of etiology would provide a welcome addition to the risk literature, the inadequacies inherent in non-genetic aetiological models have constrained risk investigators from following potential alternatives in selection. One programme of research (Rodnick \& Goldstein, 1972), clearly identified by its allegiance to a family-interaction model has emphasized to good advantage intensive laboratory and clinical investigations using the longitudinal method in working with the families of disturbed adolescents. But this investigative team is clearly a minority within the community of risk research groups.

\section{PROBLEMS POSED BY THE LONG JOURNEY TO DISORDER}

Longitudinal research is a perilous venture (Baldwin, 1960; Garmezy \& Devine, 1976). Initially, there is the problem of locating an appropriate sample; subsequently, there is the inordinately difficult task of sustaining that sample. The migratory patterns of those to be investigated, let alone those of the investigators, make follow-up research difficult. This difficulty is compounded by a growing cultural suspicion of mental health researchers, and by patients' discomfort and resistance to pursuit beyond the confines of the hospital setting.

Beyond these logistical burdens are others posed by the long-term course of a schizophrenic disorder: the critical issue of variable selection can be best understood in terms of the demands that accompany the act of selection. Investigators hope that their variables will not only relate to contemporary adaptation, but, hopefully, will also be found to predict successful versus unsuccessful adaptation at a time period ranging over a five- to fifty-year span. The results of most longitudinal studies of the growth patterns of normal youngsters would scarcely generate a spirit of optimism regarding the efficacy of long-term predictions of this sort.

Finally, there is another research reality. Longitudinal researchers are engaged in a recurrent pervasive gamble. If there is to be research pay-off it may well be realized not by the investigator but in another person's lifetime. Even more likely, however, is the probability that despite the longitudinal researcher's 'contemporary sophistication, retrospective wisdom a generation later will make him appear outdated' (Block, 1971).

A rather grim prospect. Why then do risk researchers choose such a perilous path to follow? Simply because only longitudinal research can effectively speak to fundamental questions of cause and effect in development, for only this approach, in Block's words, can 'encompass time and the trajectory of individual lives'.

\section{THE PROBLEM OF SAMPLE SIZE}

The need for broad-gauged long-term investigations means that the size of samples studied must inevitably be limited. In risk research one must deal with restricted, often atypical samples - namely 
offspring of fertile, married, co-operative and sustaining parents, often lodged in intact families. Given selection criteria such as these, there will be evident limits to the generalizations that can be drawn about schizophrenia, when adjudged against some as yet unspecified subset of potential schizophrenics-in-the-making.

\section{THE PROBLEM OF DIAGNOSIS}

Here is an ubiquitous issue. Diagnostic discrepancies abound in the study of schizophrenia across the nations of the world. US-UK differences (Cooper et al. 1972) have been the source of recent intensive investigation, as have those reported for nations varying in their levels of economic development (WHO, 1973). International differences generated in the course of ongoing observations of real patients are heightened when such diagnoses must be adduced from case records. Lewis (1957) found in his search of case-book diagnoses (admittedly stretched further back in time than those evaluated by today's risk researchers) 'obsolete terms, internal contradictions, very brief histories, and other such deficiencies' (p. 283).

Although risk researchers tend increasingly to use structured diagnostic instruments such as the Present State Examination (Wing et al. 1974) and the Current and Past Psychopathology Scales (Spitzer \& Endicott, 1968) to evaluate diagnoses, inferences as to the patient's past mental status are often still necessary if the patient has remitted prior to inclusion in the research programme.

\section{THE PROBLEM OF THE SELECTION OF VARIABLES}

Twice-cited in this editorial, variable selection remains the most demanding problem of all. How does one choose variables to predict which of today's children will be the schizophrenic patients of tomorrow? In general, investigators have tended to focus on factors present in adult schizophrenia that have served to differentiate adult patients from normal controls - a procedure which seemingly appears to be as appropriate and reasonable as any. But schizophrenics differ from normals in myriad ways; indeed, the problem experimentally has always been the unlikelihood of finding sameness. It is not surprising then to learn that the catalogue of variables now under study is a substantial one that embraces a wide spectrum of biological, psychological, social, and familial factors (Garmezy, 1975). Many, if not most of these, are bound to prove non-productive as present differentiators or future predictors. But some do appear to be more popular and, seemingly, more productive than others. These include arousal states, indicators of social and academic competence, pregnancy and birth complications in the maternal cohort, neurological evaluations, and measures of cognitive and attentional functioning. A forthcoming volume based upon the papers presented at the Second International Conference on Schizophrenia, recently held in Rochester, New York, will update the status of these and other variables now in use. It seems appropriate for now, however, to suggest that those variables which may prove to have greater predictive power will be ones that tap deficits in maturation in the earliest years of the children of schizophrenic parents, whereas, later in childhood and in adolescence, others, reflecting a failure to meet anticipated stages of cognitive, emotional and social development, or those that correlate with the growth of competence, may prove to be more effective variables for study.

\section{THE PROBLEM OF DATA ANALYSIS}

Data analysis poses a particular problem in risk research because of the difficulties presented by the the use of small, heterogeneous samples of subjects. That these $N$ 's are restricted is not a problem imposed by investigators, but by clinical realities: diversity in the clinical picture present in parental cohorts; the absence of acutely ill patients from hospital settings; high refusal rates for research participation; and the unresolved question as to whether phenotypic similarities in parents will 
prove to be reflective of psychological-biological similarities in states of disorder and their attendant processes.

An encouraging method for overcoming some of these problems is suggested by a statistical analysis performed by Hanson et al. (1976) in their recent study of the offspring of mothers who had been evaluated longitudinally for purposes unconnected with psychiatric risk. These mothers and their children had been part of a larger sample embracing twelve participating university hospitals in a Collaborative Study of Cerebral Palsy, Mental Retardation and other Neurological and Sensory Disorders of Infancy and Childhood under the auspices of the Perinatal Branch of the National Institute of Neurological Disease and Stroke (USA). Drawing upon the cases in the Minnesota sample containing a parent with a psychiatric hospitalization, the investigators provided consensus diagnoses based upon case record and MMPI data. This generated a group of thirty children with a schizophrenic parent which was then matched with a group of offspring of parents who had been hospitalized for a non-schizophrenic disorder $(N=30)$ as well as with matched $(N=29)$ and nonmatched $(N=27)$ normal control groups of children of normal parents.

Using a procedure of maximizing chi-square values, the investigators report a constellation of three discriminating variables that separated children in the risk-for-schizophrenia sample from the other groups: (1) poor motor skills in early childhood; (2) large intra-individual inconsistencies in performance on a diverse set of cognitive tasks; (3) 'observations of schizoid-like behaviours including apathy, withdrawal and emotional flatness, mixed ... with emotional instability, irritability and negativism'.

Five children who showed all 3 of these behavioural components at ages 4 and 7 each proved to be the offspring of a schizophrenic parent, suggesting that this triad may reflect an early dispositional pattern.

In a somewhat similar fashion, a group of Canadian investigators (Asarnow et al. 1976) have used a hierarchical cluster analysis derived from performance measures obtained on 10 different attentional tasks to segregate a group of children born to schizophrenic mothers and placed later in childhood in foster-home settings, from control groups of fostered and non-fostered children whose biological mothers were free of psychiatric disorder. A sub-group separated by the cluster analysis also revealed marked attentional dysfunction and personality anomalies that may also reflect an early pattern of predisposition.

Two things can be said of studies such as these. On the cautionary side is the more general observation that single studies that utilize maximizing statistical procedures demand replication since the statistical analyses are used to generate maximum differences between specific samples. Unfortunately, all too often efforts to replicate such results meet with failure. On the positive side are the findings of subgroups of children-at-risk who demonstrate performance deficits in areas long associated with schizophrenic deficit.

It is findings such as these that hearten risk investigators in their quest for those developmental attributes that may prove to be characteristic of some risk children. If one takes a long-term perspective toward such studies it can be assumed that if they are carefully conducted they will undoubtedly help to fill in our current gaps in knowledge regarding the early years of childhood of persons destined to become schizophrenic.

But risk studies may do more than that. They may also point the way toward providing a more hopeful augury of the future of many children presumed to be at risk. In his monumental work, soon to be published in English by Yale University Press, Manfred Bleuler (1972, 1974) comments on 'The offspring of schizophrenics' and provides such a note of hope. He writes:

But despite the miserable childhoods described above, and despite their presumably 'tainted' genes, most offspring of schizophrenics manage to lead normal productive lives. Indeed, after studying a number of family histories, one is left with the impression that pain and suffering can have a steeling - a hardening effect on some children, rendering them capable of mastering life with all its obstacles, just to spite their inherent disadvantages. Perhaps it would be instructive for future investigators to keep as careful watch on 
the favorable development of the majority of these children as they do on the progressive deterioration of the sick minority (1974, p. 106).

This observation by a dedicated teacher, clinician and researcher, who has spent a substantial portion of his professional life veritably as a family physician to 208 schizophrenic patients and their families, who has borne witness to their achievements, shared their hopes and aspirations, their failures and their despair, is one capable of sustaining the efforts of all those who explore the mysteries of schizophrenia.

NORMAN GARMEZY

\section{REFERENCES}

Asarnow, R. F., MacCrimmon, D. J., Cleghorn, J. F. \& Steffy, R. A. (1976). The McMaster-Waterloo Project: An attentional and clinical assessment of foster children at risk for schizophrenia. Second Rochester International Conference on Schizophrenia, Rochester, New York.

Baldwin, A. L. (1960). The study of child behavior and development. In Handbook of Research Methods in Child Development (ed. P. H. Mussen). John Wiley \& Sons: New York.

Bender, L. (1937). Behavior problems in the children of psychotic and criminal parents. Genetic Psychology Monographs 19, 229-339.

Birch, H. G. \& Gussow, J. D. (1970). Disadvantaged Children: Health, Nutrition, and School Failure. Harcourt, Brace \& World: New York.

Bleuler, M. (1972). Die schizophrenen Geistesstorungen: im Lichte langjahriger Kranken und Familiengeschichten. Verlag: Stuttgart.

Bleuler, M. (1974). The offspring of schizophrenics. Schizophrenia Bulletin 8, 93-107.

Block, J. (1971). Lives through Time. Bancroft Books: Berkeley, California.

Canavan, M. \& Clark, R. (1923). The mental health of 463 children from dementia praecox stock. Mental Hygiene 7 , 137-148.

Cooper, J. E., Kendell, R. E., Gurland, B. J., Sharpe, L., Copeland, J. R. M. \& Simon, R. (1972). Psychiatric Diagnosis in New York and London. Maudsley Monograph no. 20. Oxford University Press: London.

Erlenmeyer-Kimling, L. (1975). A prospective study of children at risk for schizophrenia: methodological considerations and some preliminary findings. In Life History Research in Psychopathology (ed. R. D. Wirt, G. Winokur \& M. Roff). University of Minnesota Press: Minneapolis.

Garmezy, N. (1974). Children at risk: the search for the antecedents of schizophrenia. II. Ongoing research programs, issues, and intervention. Schizophrenia Bulletin 9, 55-125.

Garmezy, N. (1975). The experimental study of children vulnerable to psychopathology. In Child Personality and Psychopathology: Current Topics, Vol. 2 (ed. A. Davids). John Wiley \& Sons: New York.

Garmezy, N. \& Devine, V. (1976). Longitudinal versus crosssectional research in the study of children at risk for psychopathology. In Methods of Longitudinal Research in Psychopathology (ed. J. Strauss). Plenum Press: New York. (In the press.)
Garmezy, N. \& Streitman, S. (1974). Children at risk: the search for the antecedents of schizophrenia. 1. Conceptual models and research methods. Schizophrenia Bulletin 8 , 14-90.

Hanson, D. R., Gottesman, I. I. \& Heston, L. L. (1976). Some possible childhood indicators of adult schizophrenia inferred from children of schizophrenics. British Journal of Psychiatry. (In the press.)

Kallmann, F. J. (1938). The Genetics of Schizophrenia. J. J. Augustin: New York.

Kraepelin, E. (1919). Dementia Praecox and Paraphrenia (trans. R. Mary Barclay). E. S. Livingstone: Edinburgh.

Lampron, E. M. (1933). Children of schizophrenic parents. Mental Hygiene 17, 82-91.

Lewis, A. (1957). The offspring of parents both mentally ill. Acta Genetica et Statistica Medica 7, 349-365.

Mednick, B. R. (1973). Breakdown in high-risk subjects: Familial and early environmental factors. Journal of Abnormal Psychology 82, 469-475.

Pasamanick, B. \& Knobloch, H. (1961). Epidemiologic studies on the complications of pregnancy and the birth process. In Prevention of Mental Disorders in Children (ed. G. Caplan). Basic Books: New York.

Preston, G. H. \& Antin, R. (1932). A study of children of psychotic parents. American Journal of Orthopsychiatry 2, 231-241.

Ramage, M. (1925). Mental health of children cf psychotic mothers. Unpublished Master's thesis, Smith College School for Social Work, Northampton, Mass.

Rodnick, E. H. \& Goldstein, M. J. (1972). A research strategy for studying risk for schizophrenia during adolescence and early adulthood. Presented at NIMH Conference on Risk Research, Dorado Beach, Puerto Rico.

Shakow, D. (1972). The Worcester State Hospital Research on Schizophrenia. (1927-1946). Journal of Abnormal Psychology Monograph, 80, no, 1, 67-110.

Shields, J. (1977). High risk for schizophrenia? Genetic considerations. Editorial. Psychological Medicine 7, 7-10.

Spitzer, R. L. \& Endicott, J. (1968). Current and Past Psychopathology Scales (CAPPS). Evaluations Unit, Biometrics Research. New York State Department of Mental Hygiene: New York.

Wing, J. K., Cooper, J. E. \& Sartorius, N. (1974). Measurement and Classification of Psychiatric Symptoms. Cambridge University Press: London.

World Health Organization (1973). The International Pilot Study of Schizophrenia, vol. 1. WHO: Geneva.

Yarrow, M. R., Campbell, J. D. \& Burton, R. V. (1970). Recollections of childhood: a study of the retrospective method. Monographs of the Society for Research in Child Development, serial no. 138, 35 (5). 